\title{
DOUTRINA
}

\section{AGÊNCIAS REGULADORAS DA ADMINISTRAÇÃO}

CAIO TÁCITO

$O$ direito administrativo brasileiro reflete, historicamente, a sucessão de períodos nos quais a presença do Estado se harmoniza com a participação do capital privado.

O primeiro modelo de cooperação se oferece na fase colonial quando, em Alvará de 12 de outubro de 1808, D. João VI autorizou a criação do primeiro Banco do Brasil, com capitais privados, a que se veio associar a Coroa em 1812.

Foi, contudo, na segunda metade do século XIX que se tornou significativa a mobilização tecnológica e de capitais privados, notadamente estrangeiros, no atendimento de necessidades coletivas essenciais, como estradas de ferro, iluminação pública, telefones e energia elétrica.

Firma-se o sistema de concessões de serviço público, com as regras dominantes do equilíbrio financeiro e da mutabilidade dos contratos, em correspondência às variaçōes da demanda e da técnica.

A partir da terceira década do século, a crise financeira, gerada em parte pelos efeitos da Primeira Guerra Mundial, estimulou a ampliação de atividades pelo próprio Estado, com o nascimento, na década de 20 , de entidades públicas de previdência social e a inauguração da intervenção estatal no campo da atividade produtiva.

A empresa pública ingressa na economia social e a Constituição de 1934 admite, mediante lei especial, o monopólio de determinada indústria ou atividade econômica, por motivo de interesse público (art. 116), o controle estatal de exploração de recursos naturais (art. 119, $\S 4^{\circ}$ ), a par das relações de trabalho (art. 121).

Expande-se o sistema de participação estatal. Em recenseamento federal de setembro de 1981 arrolam-se 530 pessoas jurídicas econômicas, sob a forma de autarquias, fundações e entidades paraestatais. Delas, 360 revestem a forma de sociedades de primeiro grau e subsidiárias, em todas predominando o capital público.

Nas empresas estatais (assim entendidas as empresas públicas e as sociedades de economia mista) a forma é privada, mas o substrato é publico. São satélites do regime da administração pública direta. 
A curva ascendente da presença do Estado na atividade econômica e social atinge o ápice no início da década de 80.

Até 1930 os órgãos paraestatais não iam além de 17, elevando-se a 70 na década dos anos 50, para atingir a cifra de 582 nos últimos anos do período de crescimento da participação estatal no desenvolvimento econômico e em setores nos quais se revelava ineficaz a iniciativa privada.

A partir de então se inverte o sentido da evolução, com a progressiva retração da atividade pública empresarial, segundo o critério que me permiti qualificar como o "retorno do pêndulo" (Revista de Direito Administrativo - vol. 202 - outubrodezembro de 1995, p. 1 a 10).

$\mathrm{O}$ primeiro passo de alteração da tendência expansionista da administração pública indireta se manifesta, em julho de 1979 , com o Decreto $\mathrm{n}^{\circ} 83.740$, que adota o Programa Nacional de Desburocratização, a se inaugurar no ano imediato. Em 1985, o Decreto $n^{\circ} 91.991$ aperfeiçoa o programa com a instituição do Conselho Nacional de Privatização, ao qual sucede, em 1988, o Conselho Federal de Desestatização, aprovado pelo Decreto $n^{\circ} 95.886$.

Segundo dados oficiais, no período de 1979 a 1985 , no plano federal, 20 empresas foram privatizadas, 3 transferidas a governos estaduais, outras 3 foram objeto de fusão, 14 incorporadas e 2 outras convertidas em órgãos da administração direta, no total de 42 transformações.

Uma terceira etapa do processo se aplica com o advento do Programa Nacional de Desestatização, mediante a Medida Provisória $\mathrm{n}^{\circ} 155 / 90$, convertida na Lei ${ }^{\circ}$ 8.031 , de 12 de abril do mesmo ano, e atualizada pela Lei $n^{\circ} 9.700$, de 12 de novembro de 1998.

De acordo com relatório do Tribunal de Contas sobre a gestão financeira de 1994, no período de 1990 a 1994 foram incluídas, no Programa Nacional de Desestatização, 65 empresas estatais, destacando-se, a partir de 1991, a presença, como adquirentes de ações, dos fundos de pensão da previdência que, segundo dados da Associação Brasileira de Previdência Privada, investiram, na época, mais de 2 bilhões na participação acionária, compartilhada com bancos particulares.

O direito público passa, por esta forma, a exprimir duas vertentes especiais: a política de privatização e a de desburocratização da máquina estatal e fortalecimento da associação entre o serviço público e a iniciativa privada, com a penetração mais recente do capital estrangeiro.

\section{II}

A Constituição Federal de 1988 absorve, a partir da Emenda Constitucional $\mathbf{n}^{\circ}$ 5, de 15 de agosto de 1995, a abertura dos serviços públicos ao regime privado e, com a Emenda Constitucional $n^{\circ} 8$, de 15 de agosto de 1998, dispõe sobre a concessão ou permissão nos serviços de telecomunicações e, mais significativamente ainda, com a Emenda Constitucional $n^{\circ} 9$, de 9 de novembro de 1995, extingue o monopólio estatal de exploração do petróleo, admitindo o acesso de empresas privadas. 
É importante assinalar que essas Emendas, ao mesmo passo em que abrem portas ao capital privado, determinam, de modo expresso, a criação, em lei, de um órgão público regulador da atividade privada.

É o primeiro evento no caminho da instituição legal das agências reguladoras da atividade econômica, estimulando o processo de evolução do Direito Administrativo participativo, ao qual dedicamos estudo especial (Revista de Direito Administrativo - vol. 209 - julho-setembro 1997 - p. 1 a 6).

\section{III}

A política de desburocratização se caracterizou, sob um ângulo, pela relativa autonomia de órgãos que, não obstante públicos, não mais sofrem o direto controle ministerial.

Nascem as Agências Executivas, qualificadas no Decreto $n^{\circ} 2.487$, de 2 de fevereiro de 1998, como primeiro modelo da transformação administrativa, nos moldes da reforma do Estado, em busca da chamada Administração Pública Gerencial mediante metas de desempenho.

As Agências Executivas são órgãos internos que representam um processo de desconcentração, como entes autônomos voltados para dentro da Administração Pública, conservando, portanto, natureza estatal.

Adquirem, porém, autonomia operacional, que se traduz em contratos de gestão celebrados com o Ministério competente, nos termos do art. 51 da Lei $n^{\circ} 9.649$, de 27 de maio de 1998, cuja exata observância é condição da continuidade da Agência como estipula o art. $1^{\circ}, \S 4^{\circ}$ do Decreto $n^{\circ} 2.487 / 98$.

A primeira conversão de autarquia federal em Agência Executiva ocorreu com a transformação do Instituto Nacional da Metrologia, Normatização e Qualidade Industrial (INMETRO). A mais recente é a Agência de Inteligência objeto do Decreto $\mathrm{n}^{\circ} 3.448$, de 5 de maio de 2000 .

\section{IV}

As Agências Reguladoras são outro modelo oriundo do Plano Diretor da Reforma do Estado.

Completam a liberação da atividade privada de natureza econômica, sobre a qual exercem, como representante do Estado, atuação coordenadora e normativa, em garantia do interesse coletivo que representam.

À luz do novo modelo foram, sucessivamente, criadas a Agência Nacional de Energia Elétrica (ANEEL), a Agência Nacional de Telecomunicações (ANATEL) e a Agência Nacional de Petróleo (ANP) nos correspondentes setores de energia elétrica, telecomunicações e exploração de petróleo.

Sem prejuízo da diversidade das áreas que gerenciam, as Agências Reguladoras apresentam, como pontos comuns, as seguintes características: 
- constituídas como autarquias especiais, afastam-se da estrutura hierárquica dos Ministérios e da direta influência política do Governo, com acentuado grau de independência;

- gozam de autonomia financeira, administrativa e, especialmente, de poderes normativos complementares à legislação própria do setor;

— dotadas de poderes amplos de fiscalização, operam como instância administrativa final nos litígios sobre matéria da sua competência;

- respondem pelo controle de metas de desempenho fixadas para as atividades dos prestadores de serviço, segundo diretrizes do governo e em defesa da comunidade.

Mais recentemente, foram criadas Agências Reguladoras no setor de Saúde: a Agência Nacional de Vigilância Sanitária, conforme a Lei $n^{\circ} 9.782$, de 20 de janeiro de 1999, e a Agência Nacional de Vigilância Suplementar, objeto da Lei $\mathbf{n}^{\circ} 9.782$, de 26 de janeiro de 1999, ambas alteradas em Medidas Provisórias.

Estão em andamento no Congresso Nacional projetos de lei que prevêem a criação da Agência Nacional de Transportes e a Agência Nacional de Águas, nos correspondentes setores e, a que se anuncia, o Governo Federal cuida de oferecer projeto de lei instituindo a Agência de Aviação Civil.

Nas unidades federativas, o padrão federal tem sido acompanhado em Agências Reguladoras de Serviços Concedidos, como é o caso nos Estados de São Paulo, Rio de Janeiro e Rio Grande do Sul.

\section{V}

O sistema de Agências Executivas e Reguladoras tem paradigma no direito comparado.

O regime norte-americano prevê, há muito, as figuras das "independent agencies" e das "independent regulatory agencies" cujo primeiro exemplo surge, em 1887, com a criação da Interstate Commerce Comission (ICC) e se estende a mais de meia dezena, arroladas no Manual da Organização Administrativa dos Estados Unidos (United States Government Organization Manual).

A chamada "regulation" compreende duas grandes áreas: a regulação econômica e a regulação social, envolvendo, a par da alteração normativa, a interpretação que formaliza a jurisprudência uniforme como roteiro operacional no setor, como destaca ANGEL MANUEL MORENO MOLINA em completo e documentado estudo sobre "La Administración por Agencias en los Estados Unidos de Norteamerica" (Madrid - 1995).

$\mathrm{Na}$ Inglaterra o modelo de privatização, inaugurado em 1984 e amplamente desenvolvido no governo conservador, implantou o processo de "regulation" em diversos setores econômicos sob variados esquemas que caracterizam, na expressão de MATTHEW BISHOP, JOHN KAY e COLIN MAYER o "desafio regulador" ("The Regulatory Challenge" - 1995). 
Experiências equivalentes de entes regulatórios se destacam na Espanha, na Argentina e em outros países, merecendo identificar-se como uma moderna tendência universal.

Feição típica das agências reguladoras é a independência que merece sua administração em face da estrutura hierárquica.

Em maior ou menor proporção, as Agências são geridas por direções colegiadas com mandatos certos e determinados, imunes à discricionariedade do Poder Executivo, como evidencia em estudo específico DIOGO DE FIGUEIREDO MOREIRA NETTO (Boletim de Direito Administrativo da Editora NDJ Ltda. - $\mathrm{n}^{\circ}$ 6, Ano XVI, junho de $2000-$ p. 416).

O Supremo Tribunal Federal declarou a inconstitucionalidade de lei gaúcha que determinava a competência da Assembléia Legislativa para livre destituição de conselheiros da Agência Reguladora de Serviços Concedidos do Rio Grande do Sul (AGERGS). O voto do Ministro Sepúlveda Pertence, acolhido pela unanimidade do Tribunal, faz sobressair o princípio de que a dispensa somente é admissível se for justificada mediante processo administrativo, com direito de defesa.

Destacou o Ministro Nelson Jobim, em seu voto, a inviabilidade de o Executivo destituir seus integrantes sem motivação.

Neste sentido, as leis federais sobre agências reguladoras condicionam a exoneração de conselheiros à antecedência de processos administrativos de responsabilidade, assegurando por esta forma a estabilidade do órgão dirigente da agência.

A função das Agências Reguladoras - objeto de valiosa e abundante bibliografia nacional - mantém o adequado equilíbrio entre a política de privatização e a preservação do interesse público, harmonizando a liberdade com a adequação dos fins básicos da manutenção dos interesses da comunidade.

A privatização transfere o serviço público à gestão privada. $O$ poder público retém, contudo, a supervisão sobre o exercício regular da atividade, em garantia os conselheiros e usuários, na preservação do interesse geral, que o Estado representa.

E a liberdade decisória das Agências Reguladoras não as dispensa do respeito ao princípio da legalidade e aos demais fixados para a Administração Pública, no art. 37 da Constituição Federal de 1988, inclusive o princípio da eficiência incluído pela Emenda Constitucional n ${ }^{\circ} 19 / 98$.

Em suma, na síntese feliz de DIOGO FIGUEIREDO MOREIRA NETO,

“De certo modo, portanto, e até paradoxalmente, a privatização da execução de serviços, empreendida pela reforma do Estado, neste fim de século, termina sendo uma publicização de sua regulamentação e controle" (Mutações do Direito Administrativo - edição Renovar 2000 - p. 148). 


\section{Índice Analítico da Revista de Direito Administrativo - RDA}

Vols. 140 a 186

Vols. 187 a 198

Vols. 199 a 210

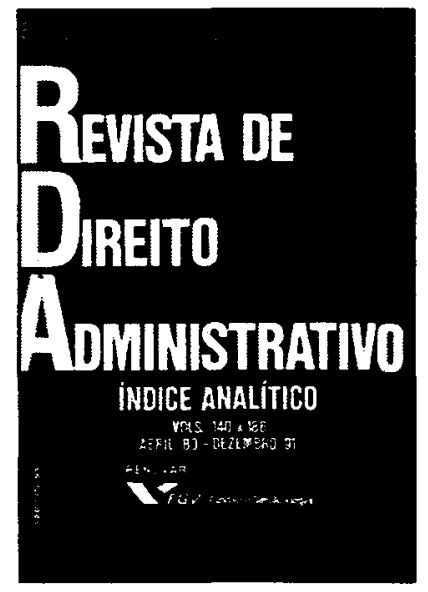

Indispensável como fonte de consulta para facilitar a localização, sem perda de tempo, dos respectivos assuntos apresentados na Revista de Direito Administrativo.

$\begin{array}{lll}\text { Ref. 0055 } & \text { Ref. 0089 } & \text { Ref. 0177 } \\ \text { Cartonado } & \text { Form. 16x23 } & 1991-1998\end{array}$

\section{Instituições Civis no Direito do Trabalho}

Alexandre Agra Belmonte

De conceitos atuais, de exemplos e com linguagem de fácil compreensão, não obstante a profundidade com que são tratados os temas estudados, trata-se de obra indispensável aos aspirantes da magistratura e procuradoria do trabalho, compreensiva de toda a matéria dos respectivos concursos, advogados, universitários, professores e todos os demais profissionais que militam na área trabalhista. O livro atenta para os fatos jurídicos, porque ele dá uma perfeita noção do significado e alcance da obra, bem como de sua utilizaçāo prática.

Ref. 0078

Form. 14x21

Brochura 1997

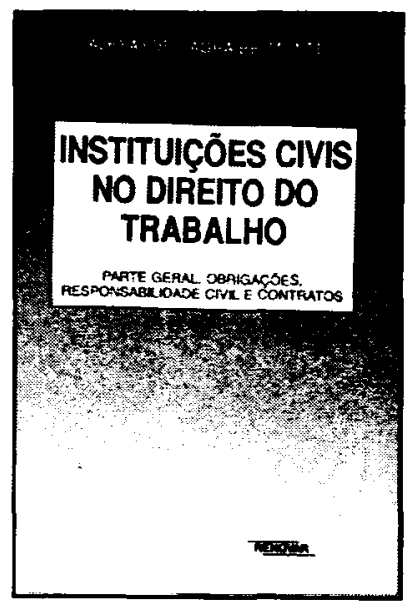

